\title{
Screening of serum 25-hydroxyvitamin $D$ levels among elderly Egyptians admitted to the orthogeriatric unit by fracture hip
}

\author{
Ahmed Rabiee $^{1 *}$ D, Mohamed AboElsoud ${ }^{2}$, Sayed M. Seif El Nasr ${ }^{1}$ and Sameh Abouzeid ${ }^{3}$
}

\begin{abstract}
Background: Vitamin D deficiency increases muscle weakness and pain leading to reduced power and function, increased bone turnover and increased risk of falls and hip fractures in elderly. We postulated that vitamin $D$ deficiency in sunny Egypt should be lower than western countries so we screen for prevalence of vitamin $D$ deficiency among all elderly patient admitted to orthogeriatric unit by fracture hip.

Results: Our study showed that vitamin D deficiency is common in elderly Egyptian patients admitted to orthogeriatric unit with hip fractures.

Of the study group (n 290 patients) vitamin D levels were sufficient (30 ng/dl or more) in 24 patients (8.3\%) and insufficient (between $20 \mathrm{ng}$ and $30 \mathrm{ng}$ ) in 125 patients (43.1\%) and deficient (less than 20) in 141 patients (48.7\%). Among the study group, female patients had lower levels of vitamin D (18.8 \pm 6.9$)$ compared to males (20.5 \pm 6.7) $P$ value 0.034 .

Although our study failed to link different levels of vitamin D with activity of daily life: $P$ value was (0.116) in bathing, (0.058) in dressing, (0.115) in toileting and (054) in transfer.

A little difference was found in feeding (0.036) and previous fall (0.011) and cognitive impairment; MiniCOG $<3 P$ value 0.017. Both previous falls and cognitive decline are in turn linked to increased fracture risk

Conclusion: Hypovitaminosis D is common among older patients with hip fractures even in sunny Egypt remaining slightly lower than its prevalence in western countries. Although no direct significant correlations with activity of daily life, vitamin D deficiency was associated with higher risks of previous falls and cognitive impairment both in turn increases the risk of fractures.
\end{abstract}

\section{Background}

Nearly a billion suffer vitamin D deficiency or insufficiency worldwide, being more prevalent among elderly [1].

Vitamin D deficiency increases muscle weakness and pain leading to reduced muscle power and function [2], increased bone demineralization [3], and higher risk of falls and hip fractures in elderly [4].

With aging, vitamin D deficiency increases because of inadequate sunlight exposure and lower cutaneous formation of vitamin $\mathrm{D}$, lower dietary intake of vitamin $\mathrm{D}$,

\footnotetext{
* Correspondence: ahmedrabeeh2020@yahoo.com

${ }^{1}$ KasrAlainy School of medicine, Cairo University, Cairo, Egypt

Full list of author information is available at the end of the article
}

defective intestinal absorption, and Impaired 1 and 25 hydroxylation [1].

In western countries vitamin $\mathrm{D}$ deficiency is more common in elderly patients due to impaired cutaneous synthesis during winter months $[5,6]$ both in housebound [7] and in medical inpatients [8].

Prevalence of vitamin D deficiency is even higher in elderly patients with fragility fractures reaching about 55 to $91.6 \%[9,10]$.

Many observational studies fail to find a dependent relationship between vitamin D levels and frailty, while only few interventional studies yielding a positive effect

\section{Springer Open}

(- The Author(s). 2020 Open Access This article is licensed under a Creative Commons Attribution 4.0 International License, which permits use, sharing, adaptation, distribution and reproduction in any medium or format, as long as you give appropriate credit to the original author(s) and the source, provide a link to the Creative Commons licence, and indicate if changes were made. The images or other third party material in this article are included in the article's Creative Commons licence, unless indicated otherwise in a credit line to the material. If material is not included in the article's Creative Commons licence and your intended use is not permitted by statutory regulation or exceeds the permitted use, you will need to obtain permission directly from the copyright holder. To view a copy of this licence, visit http://creativecommons.org/licenses/by/4.0/. 
Table 1 Descriptive data of the study group

\begin{tabular}{|c|c|c|}
\hline Bathing & $N$ & $\%$ \\
\hline Dependent & 219 & 75.50 \\
\hline Independent & 71 & 24.50 \\
\hline Dressing & $N$ & $\%$ \\
\hline Dependent & 236 & 81.40 \\
\hline Independent & 54 & 18.60 \\
\hline Toilet & $N$ & $\%$ \\
\hline Dependent & 242 & 83.40 \\
\hline Independent & 48 & 16.60 \\
\hline Transfer & $N$ & $\%$ \\
\hline Dependent & 229 & 79.00 \\
\hline Independent & 61 & 21.00 \\
\hline Feeding & $N$ & $\%$ \\
\hline Dependent & 240 & 82.80 \\
\hline Independent & 50 & 17.20 \\
\hline Continence & $N$ & $\%$ \\
\hline Incontinent & 67 & 23.10 \\
\hline Continent & 223 & 76.90 \\
\hline Falls & $N$ & $\%$ \\
\hline No & 214 & 73.80 \\
\hline Yes & 76 & 26.20 \\
\hline MiniCOG & $N$ & $\%$ \\
\hline$>3$ & 210 & 72.40 \\
\hline 3 or less & 80 & 27.60 \\
\hline
\end{tabular}

of vitamin D supplements on frailty, mainly due to improvement in the physical performance parameters [11].

Egypt is described as the land of the sun with a desert and semi desert climate and the sun shines throughout the year (https://www.wildland.com/details-egypt-seasons\&climate). So, we postulated that vitamin D deficiency in Egypt should be lower than in the countries with seasonal winters.

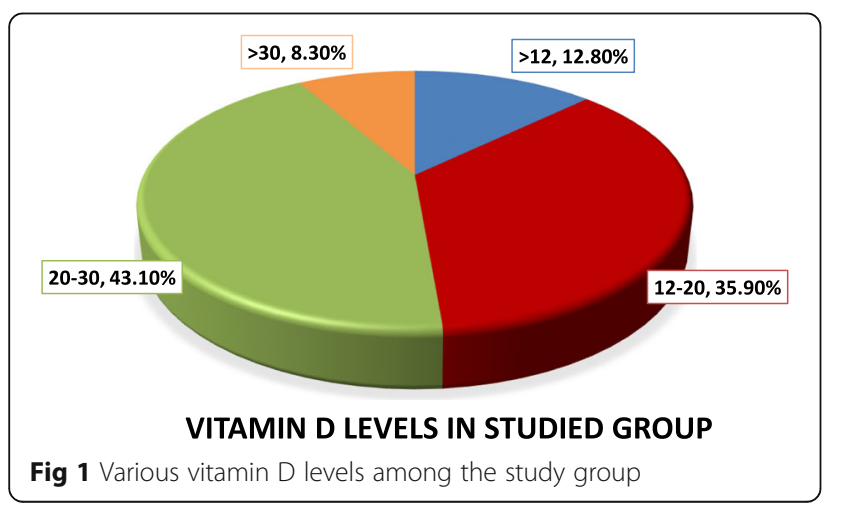

Table 225 hydroxy vitamin D levels in both sexes

\begin{tabular}{llll}
\hline & \multicolumn{2}{l}{$\mathbf{2 5}$ hydroxy vitamin $\mathbf{D}$} & $\boldsymbol{P}$ value \\
\cline { 2 - 3 } & Mean \pm SD & Median (IQR) & \\
\hline Female & $18.8 \pm 6.9$ & $17.5(13.7: 22.8)$ & $\mathbf{0 . 0 3 4}$ \\
Male & $20.5 \pm 6.7$ & $21(14.9: 24)$ & \\
\hline
\end{tabular}

\section{Methods}

We enrolled a prospective observational study over 290 patients aged older than 60 years admitted to orthogeriatric unit (OGU) with hip fractures between November 2017 and June 2019.

Admission of male patients to OGU started at October 2017 with four beds. While to the female OGU (four beds) started 4 months later.

After ethical approval by local ethical committee of internal medicine department faculty of medicine at 25 October 2017, written informed consents were obtained from all participants.

All patients are subjected to: geriatric functional assessment [12] including age, sex, and history of previous falls ( $\mathrm{Y}$ or $\mathrm{N}$ ) and the pre-fracture state including: premorbid mobility, mini Cog (score 3 or less), activity of daily life (ADLs); bathing, dressing, toileting, transfer, feeding, and grooming (described as dependant or independent).

Mini-Cog: an easy test for cognitive functional assessment consists of two parts: three item recall and clock draw test (CDT) and is superior to mini mental state examination in identifying mild cognitive impairment irrespective the age or educational level [13].

CDT: serves as the recall distracter where patients are asked to draw the hands of the clock to make a specific time in a clock face.

CDT in a cross sectional study over geriatric patients from outpatient clinics with heterogeneous educational levels showed high sensitivity and specificity even in people with lower education [14].

Laboratory assessment of $\mathrm{Ca}$, phosphorus, Albumen, TSH, FreeT4, Urea and Creatinine, $25(\mathrm{OH})$ vitamin D level. Using Holick classification [2] vitamin D deficiency is considered with vitamin $\mathrm{D}$ level $<20 \mathrm{ng} / \mathrm{mL}$, insufficiency with vitamin D level 21 to $29 \mathrm{ng} / \mathrm{mL}$, and normal vitamin $\mathrm{D}$ levels are defined as $30 \mathrm{ng} / \mathrm{mL}$ or more.

The 25-hydroxyvitamin D3 was measured using the Roche Elecsys vitamin-D3 assay (Roche Mannheim, Germany) in the hospital's laboratory.

We excluded patients with impaired renal functions, abnormal thyroid function, and other fractures.

\section{Study's outcomes}

The primary outcome is to screen for prevalence of vitamin D deficiency among all elderly patient admitted to OGU by fracture hip The secondary outcomes included 
the correlation of vitamin D levels to other functional geriatric assessment parameters.

\section{The statistical analysis}

Statistical analysis was performed with SPSS statistical software, version 21. Continuous data were described as mean \pm standard deviation (SD).

- Description of qualitative variables as number and percent

o Mann-Whitney test was used instead of independent t-test to compare quantitative variables between two groups in non-parametric data (SD > 30\% mean).

- Kruskal-Wallis test was used instead of one-way ANOVA to compare quantitative variables between more than two groups in non-parametric data and pair wise comparison used in case of significant variables

- Chi-square test used to compare between qualitative variables and exact correction when cell contain count less than 5

o Pearson correlation used to test for linear relation between vitamin $\mathrm{D}$ and other quantitative variables $P \leq 0.05$ significant while $P<0.01$ highly significant.

\section{Results}

We screened 290 patients $>60$ years with the mean age $67 \pm 6.7$ years admitted over 20 months to orthogeriatric unit of them 158 were males (54.5\%) and 132 were females (45.5\%).

Of the study group 193 (66.6\%) patients were smokers and 97 (33.4\%) were non-smokers.

One year before the fracture 229 (79\%) patients were ambulant and 61 (21\%) were using walking aids.

\section{Demographic data are shown in Table 1}

Vitamin D levels were sufficient (30 ng/dl or more) in 24 patients (8.3\%) and insufficient (between $20 \mathrm{ng}$ and $30 \mathrm{ng}$ ) in 125 patients (43.1\%) and deficient (less than 20) in 141 patients (48.7\%) among the study group (Fig. 1)

Vitamin D levels were significant lower among female patients $(18.8 \pm 6.9)$ compared to male patients $(20.5 \pm$ 6.7) $P$ value (0.034) (Table 2).

Also we noticed that vitamin $\mathrm{D}$ levels were positively correlated to calcium and phosphorus (Table 3).

Although our study failed to link different levels of vitamin $\mathrm{D}$ with activity of daily life: $P$ value was (0.116) in bathing, (0.058) in dressing, (0.115) in toileting, and (054) in transfer. A little difference was found in feeding (0.036) and previous fall (0.011) and

Table 3 Descriptive of all quantitative variables

\begin{tabular}{|c|c|c|c|c|c|}
\hline Age & $<12$ & $12-20$ & $20-30$ & $>30$ & $P$ value \\
\hline Mean \pm SD & $65 \pm 4$ & $65 \pm 3.7$ & $64.7 \pm 3.6$ & $64.7 \pm 3$ & 0.862 \\
\hline Median (IQR) & $64(62: 66)$ & $65(62: 67)$ & $64(62: 67)$ & $64.5(62.5: 66.5)$ & \\
\hline \multicolumn{6}{|l|}{ CA } \\
\hline Mean \pm SD & $7.7 \pm 0.6$ & $8.4 \pm 0.4$ & $8.7 \pm 0.3$ & $8.9 \pm 0.3$ & $<0.001$ \\
\hline Median (IQR) & $7.9(7.2: 8.23)$ & $8.4(8.3: 8.6)$ & $8.7(8.4: 9.03)$ & $8.8(8.6: 9.1)$ & \\
\hline \multicolumn{6}{|l|}{ PHOSP } \\
\hline Mean \pm SD & $2.5 \pm 0.7$ & $2.7 \pm 0.5$ & $3.8 \pm 0.4$ & $3.8 \pm 0.4$ & $<0.001$ \\
\hline Median (IQR) & $2.8(1.8: 2.97)$ & $2.9(2.2: 3.13)$ & $3.9(3.6: 4.1)$ & $3.9(3.5: 4.11)$ & \\
\hline \multicolumn{6}{|l|}{ Albumin } \\
\hline Mean \pm SD & $3.8 \pm 0.4$ & $3.7 \pm 0.4$ & $3.7 \pm 0.5$ & $3.7 \pm 0.4$ & 0.996 \\
\hline Median (IQR) & $3.9(3.6: 3.99)$ & $3.9(3.5: 4)$ & $3.9(3.5: 4)$ & $3.9(3.8: 4)$ & \\
\hline \multicolumn{6}{|l|}{ Creatinine } \\
\hline Mean $\pm S D$ & $1.1 \pm 0.1$ & $1 \pm 0.2$ & $1 \pm 0.1$ & $1 \pm 0.1$ & 0.051 \\
\hline Median (IQR) & $1.1(1.1: 1.16)$ & $1.1(1: 1.15)$ & $1(0.9: 1.1)$ & $1.1(0.9: 1.13)$ & \\
\hline \multicolumn{6}{|l|}{ TSH } \\
\hline Mean $\pm S D$ & $2.5 \pm 1$ & $3.3 \pm 0.9$ & $2.8 \pm 1$ & $1.9 \pm 0.4$ & 0.062 \\
\hline Median (IQR) & $2.2(1.8: 3.4)$ & $3.8(2.8: 3.99)$ & $2.9(1.8: 3.88)$ & $1.9(1.7: 2.15)$ & \\
\hline \multicolumn{6}{|l|}{ FT4 } \\
\hline Mean \pm SD & $1.1 \pm 0.2$ & $1 \pm 0.2$ & $1.1 \pm 0.2$ & $1 \pm 0.2$ & 0.061 \\
\hline Median (IQR) & $1.1(1.1: 1.2)$ & $1(0.9: 1.09)$ & $1.1(1: 1.2)$ & $0.9(0.8: 1.2)$ & \\
\hline
\end{tabular}

Regarding age no statistically significant difference

Regarding $\mathrm{Ca}$ and phosphorus. There was statistically significant increase in Ca and phosphorus levels with higher vitamin D level

Regarding creatinine, TSH, and free T4. There was no statistically significant difference 
Table 4 Correlations between 25 hydroxy vitamin D levels and comprehensive geriatric assessment

\begin{tabular}{|c|c|c|c|c|c|}
\hline \multirow[t]{2}{*}{ ADLs } & \multicolumn{4}{|c|}{25 hydroxy vitamin D levels } & \multirow[b]{2}{*}{$P$ value } \\
\hline & $>12$ & $12-20$ & $20-30$ & $>30$ & \\
\hline Premorbid mobility & $N(\%)$ & $N(\%)$ & $N(\%)$ & $N(\%)$ & \\
\hline Aid & $17(15)$ & $47(41.6)$ & $43(38.1)$ & $6(5.3)$ & 0.138 \\
\hline Ambulatory & $20(11.3)$ & $57(32.2)$ & $82(46.3)$ & $18(10.2)$ & \\
\hline \multicolumn{6}{|l|}{ Bathing } \\
\hline Dependent & $24(11)$ & 77 (35.2) & $102(46.6)$ & $16(7.3)$ & 0.116 \\
\hline Independent & $13(18.3)$ & $27(38)$ & $23(32.4)$ & $8(11.3)$ & \\
\hline \multicolumn{6}{|l|}{ Dressing } \\
\hline Dependent & $25(10.6)$ & $83(35.2)$ & $106(44.9)$ & $22(9.3)$ & 0.058 \\
\hline Independent & $12(22.2)$ & $21(38.9)$ & $19(35.2)$ & $2(3.7)$ & \\
\hline \multicolumn{6}{|l|}{ Toilet } \\
\hline Dependent & $27(11.2)$ & $84(34.7)$ & $109(45)$ & $22(9.1)$ & 0.115 \\
\hline Independent & $10(20.8)$ & $20(41.7)$ & $16(33.3)$ & $2(4.2)$ & \\
\hline \multicolumn{6}{|l|}{ Transfer } \\
\hline Dependent & $25(10.9)$ & $82(35.8)$ & $106(46.3)$ & $16(7)$ & 0.054 \\
\hline Independent & $12(19.7)$ & $22(36.1)$ & 19 (31.1) & $8(13.1)$ & \\
\hline \multicolumn{6}{|l|}{ Feeding } \\
\hline Dependent & $25(10.4)$ & $85(35.4)$ & $108(45)$ & $22(9.2)$ & 0.036 \\
\hline Independent & $12(24)$ & $19(38)$ & $17(34)$ & $2(4)$ & \\
\hline Continent & $N(\%)$ & $N(\%)$ & $N(\%)$ & $N(\%)$ & \\
\hline Incontinent & 13 (19.4) & $27(40.3)$ & $22(32.8)$ & $5(7.5)$ & 0.127 \\
\hline Continent & $24(10.8)$ & 77 (34.5) & $103(46.2)$ & $19(8.5)$ & \\
\hline \multicolumn{6}{|l|}{ Falls } \\
\hline No & $21(9.8)$ & 76 (35.5) & $102(47.7)$ & $15(7)$ & 0.011 \\
\hline Yes & $16(21.1)$ & $28(36.8)$ & $23(30.3)$ & $9(11.8)$ & \\
\hline \multicolumn{6}{|l|}{ MiniCOG } \\
\hline$>3$ & $22(10.5)$ & 70 (33.3) & $102(48.6)$ & $16(7.6)$ & 0.017 \\
\hline 3 or less & 15 (18.8) & $34(42.5$ & $23(28.8$ & $8(10$ & \\
\hline
\end{tabular}

cognitive impairment; MiniCOG $<3 \quad P$ value $(0.017)$ (Table 4).

\section{Discussion}

In this study we found that vitamin D deficiency is common in older patients presenting with hip fractures even in sunny Egypt. Of 290 elderly patients with hip fracture, vitamin D levels were sufficient in only 24 patients (8.3\%) and insufficient in 125 patients (43.1\%) and deficient in 141 patients (48.7\%).

These percentages are slightly lower than the prevalence in western countries (55 to 91.6\%) [15]. Where some middle east studies have shown a high prevalence of vitamin D deficiency (49.4-100\%) in the middle east despite sunny climate, conservative clothing style has been identified as a risk factor $[16,17]$.
Also in the present study lower levels of vitamin D in female patients with hip fracture mirrors the image at western countries [4].

Lower levels of vitamin D are associated with more frequent falls which is consistent to Women Health Initiative (WHI) study that demonstrated that with fall of vitamin $\mathrm{D}$ deficiency odds ratio for hip fracture nearly doubles [4].

Our study showed that lower levels of vitamin D are associated with more decline in cognitive function as agreed by several studies which have linked vitamin $\mathrm{D}$ deficiency and basic and executive cognitive functions [18].

Although our study failed to link different levels of vitamin $\mathrm{D}$ with activity of daily life: $P$ value was $(0.116)$ in bathing, (0.058) in dressing, (0.115) in toileting, and $(0.54)$ in transfer. A little difference was found in feeding (0.036) and previous fall (0.011) and cognitive 
impairment; MiniCOG $<3 P$ value 0.017 . Both previous fall and cognitive decline are linked to increased fracture risk [18].

There are few studies in the elderly about the total 25 hydroxy vitamin $\mathrm{D}$ statuses and functional independence relationship [19-23]. Three of these studies have found a positive association between vitamin $\mathrm{D}$ level and ADL. Houston and colleagues [19], Nakamura and colleagues [20] revealed that vitamin D deficiency was a predictor of low ADL scores in community-dwelling adults of advanced age. Also, Kotlarczyk and colleagues showed that women in long-term care facilities, who had low levels of vitamin $\mathrm{D}$, had the greatest functional decline [21].

On the other hand, two studies with no association between vitamin D and ADL was found, and NavarroMartínez and colleagues did not find an association between the vitamin D level and ADLs in frail octogenarian women [22]. Also, Formiga and colleagues showed no association between vitamin D status and IADLs, but a positive relationship between vitamin $\mathrm{D}$ level and $\mathrm{ADL}$ score was found [23].

Several limitations of this study should be mentioned; first, we missed the living areas (rural versus urban). Second, the nutritional state was not assessed. Another limitation is missing the data about receiving vitamin D supplementation before admission. But many systematic reviews and meta-analysis of hip fracture risk in relation to vitamin D supplementation argue that neither higher nor lower doses vitamin D supplementations prevented hip fracture, although these reviews were mainly uncontrolled observational studies [24, 25].

\section{Conclusion}

Hypovitaminosis D is common among older patients with hip fractures even in sunny Egypt but remains slightly lower than its prevalence in western countries. Although not significantly linked to activity of daily life, it was associated with higher risks of previous falls and cognitive impairment both of them in turn increases the risk of fractures.

\section{Abbreviations}

ADLs: Daily life activities; IDLA: Instrumental daily life activity; MINI

COG: Cognition; WHI: Women Health Initiative

\section{Acknowledgements}

Professor Maha HossamEldin, professor of Internal Medicine and head of Geriatric Department, KasrAlainy School of Medicine, Cairo University.

\section{Authors' contributions}

AR and MAS designed the study and wrote the final manuscript, SMS collected the data and SAZ analyzed the collected data. All authors have read and approved the manuscript.

\section{Availability of data and materials}

The datasets used and analyzed during the current study are available from the corresponding author on reasonable request.

\section{Ethics approval and consent to participate}

Written informed consents approved by local ethical committee of Internal Medicine Department, Faculty of Medicine, Cairo University, was obtained from all participants in 25 October 2017. No ethical approval number is applicable.

\section{Consent for publication}

All patients included in this research gave written informed consent to publish the data contained within the study.

\section{Competing interests}

None.

\section{Author details}

${ }^{1}$ KasrAlainy School of medicine, Cairo University, Cairo, Egypt. ${ }^{2}$ KasrAlainy School of medicine, Cairo University, Cairo, Egypt. ${ }^{3}$ Nephrology Department, Theodor Bilharze Research Institute, Cairo, Egypt.

Received: 26 July 2020 Accepted: 13 October 2020

Published online: 05 November 2020

\section{References}

1. Sahota O (2014) Understanding vitamin D deficiency. Age Ageing 43:589591

2. Holick MF (2007) Vitamin D deficiency. N Engl J Med. 357(3):266-281

3. Mezuita-Raya P, Muñoz-Torres M et al (2001) Relation between vitamin D insufficiency, bone density, and bone metabolism in healthy postmenopausal women. J Bone Miner Res. 16(8):1408-1415

4. Cauley JA, LaCroix AZ, Wu L (2008) Serum 25-Hydroxyvitamin D Concentrations and Risk for Hip Fractures. Ann Intern Med. 149(4):242-250

5. Looker AC, Dawson-Hughes B, Calvo MS (2002) Serum 25- hydroxyvitamin $D$ status of adolescents and adults in two seasonal subpopulations from NHANES III. Bone. 30(5):771-777

6. Nurmi I, Kaukonen JP, Lu"thje P et al (2005) Half of the patients with acute hip fracture suffer from hypovitaminosis D: a prospective study in southeastern Finland. Osteoporos Int. 16(12):2018-2024

7. Lips P (2001) Vitamin D deficiency and secondary hyperparathyroidism in the elderly: consequences for bone loss and fractures and therapeutic implications. Endocr Rev. 22(4):477-501

8. Thomas MK, Lloyd-Jones DM, Thadhani RI et al (1998) Hypovitaminosis D in medical inpatients. N Engl J Med. 338(12):777-783

9. Moniz C, Dew T, Dixon T (2005) Prevalence of vitamin D inadequacy in osteoporotic hip fracture patients in London. Curr Med Res Opin. 21(12): 1891-1894

10. Beringer $T$, Heyburn $G$, Finch $M$ et al (2006) Prevalence of vitamin D inadequacy in Belfast following fragility fracture. Curr Med Res Opin. 22(1): 101-105

11. Wong $Y Y$, Flicker L (2015) Hypovitaminosis D and frailty: Epiphenomenon or causal? Maturitas. 82(4):328-335

12. Cohen HJ, Feussner JR, Weinberger M et al (2002) A controlled trial of inpatient and outpatient geriatric evaluation and management. NEJIM 346: 905-912

13. Carenero-Pardo C et al (2013) Utility of the Mini-Cog for detection of cognitive impairment in primary care: data from two Spanish studies. International Journal of Alzheimer disease:285462-285467

14. Francisca J et al (2012) Clock drowning test in elderly individual with different educational level: correlation with clinical dementia rating. Am J Alzheimer Dis Other Demen. 27(8):620-624

15. Bischoff-Ferrari HA, Can U, Staehelin HB et al (2008) Severe vitamin D deficiency in Swiss hip fracture patients. Bone. 42(3):597-602

16. Al-Mogbel ES (2012) Vitamin D status among adult Saudi Females visiting primary health care clinics. Int J Health Sci (Qassim). 6(2):116-126

17. Golgahar J, Al-Saffar N, Altayab Diab D, Al-Othman S, Darwish A, Al-Kafaji G (2014) Predictors of vitamin D deficiency and insufficiency in adult Bahrainis: a cross-sectional study. Public Health Nutr. 17(4):732-738 
18. Cherniack EP, Troen BR, Florez HJ et al (2009) Some new food for thought: The role of vitamin D in the mental health of older adults. Curr Psychiatry Rep 11:9-12

19. Houston Denise K, Tooze Janet A, Davis Cralen C et al (2011) Serum 25hydroxyvitamin $D$ and physical function in older adults: the cardiovascular health study all stars. J Am Geriatr Soc 59:1793-1801

20. Nakamura K, Nishiwaki T, Ueno K, Yamamoto M (2005) Serum 25 hydroxyvitamin D levels and activities of daily living in non institutionalized elderly Japanese requiring care. J Bone Miner Metab 23:488-494

21. Kotlarczyk MP, Perera S, Ferchak MA, Nace DA, Resnick NM, Greenspan SL (2017) Vitamin D deficiency is associated with functional decline and falls in frail elderly women despite supplementation. Osteoporos Int 28:1347-1353

22. Navarro-Martínez R, Fernández-Garrido J, Buigues C, Martinez, et al. (2015) Serum vitamin $D$ and functional impairment in octogenarian women. Appl Nurs Res 30:10-14

23. Formiga F, Ferrer A, Almeda J, San Jose A, Gil A, Pujol R (2011) Utility of geriatric assessment tools to identify 85 -years-old subjects with vitamin $D$ deficiency. J Nutr Health Aging 15:110-114

24. Holick MF, Binkley NC, Bischoff-Ferrari HA et al (2011) Evaluation,treatment and prevention of vitamin D deficiency: an Endocrine Society clinical practice guideline. J Clin Endocrinol Metab. 96(7):1911-1930

25. Lai JKC, Lucas RM, Clements MS, Roddam AW, Banks E (2010) Hip fracture risk in relation to vitamin $D$ supplementation and serum 25 -hydroxyvitamin D levels: a systematic review and metaanalysis of randomized controlled trials and observational studies. BMC Public Health. 10:331

\section{Publisher's Note}

Springer Nature remains neutral with regard to jurisdictional claims in published maps and institutional affiliations.

\section{Submit your manuscript to a SpringerOpen ${ }^{\circ}$ journal and benefit from:}

- Convenient online submission

- Rigorous peer review

- Open access: articles freely available online

- High visibility within the field

- Retaining the copyright to your article

Submit your next manuscript at $\boldsymbol{\nabla}$ springeropen.com 